\title{
Adjuvant treatment delay in breast cancer patients
}

\author{
Damila Cristina Trufelli ${ }^{*}$, Leandro luongo de Matos $^{2}$, Patricia Xavier Santi ${ }^{3}$, Auro Del Giglio ${ }^{4}$ \\ ${ }^{1}$ University/college education - Coordinator of the Oncology Service at the Hospital de Ensino Padre Anchieta, Santo André, SP, Brazil \\ ${ }^{2}$ Habilitation (BR: Livre Docência) - Auxiliary Professor of Public Health (biostatistics) at Faculdade de Medicina do ABC, Santo André, SP, Brazil \\ ${ }^{3}$ University/college education - Coordinator of the Oncology Service at Hospital Estadual Mario Covas, Santo André, SP, Brazil \\ ${ }^{4}$ Habilitation (BR: Livre Docência) - Full Professor of Hematology and Oncology at Faculdade de Medicina do ABC, Santo André, SP, Brazil
}

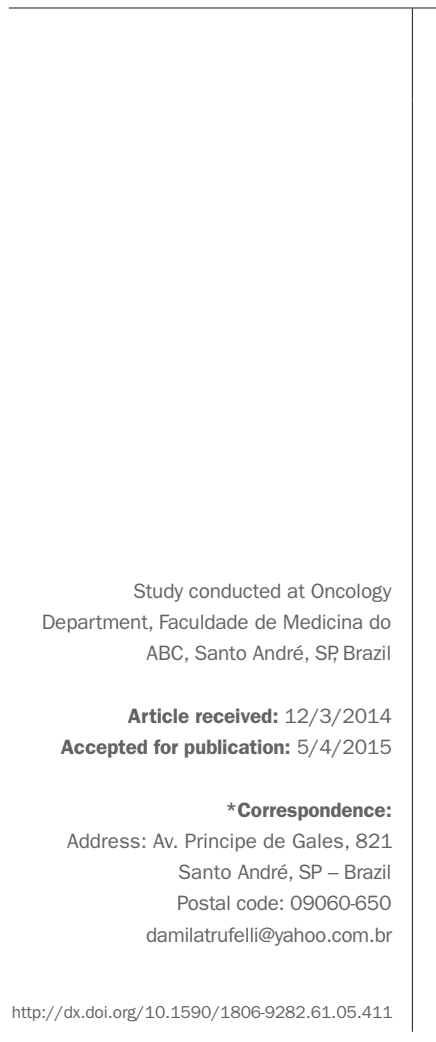

\section{SUMMARY}

Background: to evaluate if time between surgery and the first adjuvant treatment (chemotherapy, radiotherapy or hormone therapy) in patients with breast cancer is a risk factor for lower overall survival (OS).

Method: data from a five-year retrospective cohort study of all women diagnosed with invasive breast cancer at an academic oncology service were collected and analyzed.

Results: three hundred forty-eight consecutive women were included. Time between surgery and the first adjuvant treatment was a risk factor for shorter overall survival ( $\mathrm{HR}=1.3$, 95CI 1.06-1.71, $\mathrm{p}=0.015$ ), along with negative estrogen receptor, the presence of lymphovascular invasion and greater tumor size. A delay longer than 4 months between surgery and the first adjuvant treatment was also associated with shorter overall survival (cumulative survival of $80.9 \%$ for delays $\leq 4$ months $v$ s. $72.6 \%$ for delays $>4$ months; $\mathrm{p}=0.041$, log rank test).

Conclusion: each month of delay between surgery and the first adjuvant treatment in women with invasive breast cancer increases the risk of death in 1.3-fold, and this effect is independent of all other well-established risk factors. Based on these results, we recommend further public strategies to decrease this interval.

Keywords: breast neoplasms, time-to-treatment, prognosis, survival, health care quality assurance.

\section{INTRODUCTION}

Breast cancer is the most prevalent neoplasm in women in Brazil and around the world. ${ }^{1}$ In less-developed countries, breast cancer is frequently diagnosed in advanced stages, which leads to a decrease in overall survival rates. ${ }^{2}$ There are other variables that also influence the prognosis of these patients, including age, lymph node status, hormone receptor status, histologic grade and tumor size. ${ }^{3-5}$ In addition to these variables, some studies have shown that delays in the initiation of breast cancer treatment can also lead to a worse prognosis. ${ }^{2,6}$

However, this remains a controversial issue in the literature; while some studies define that a three-month or longer delay between diagnosis and treatment can decrease survival in up to $12 \%,{ }^{7-9}$ others argue that time until treatment does not influence the survival rates of women with breast cancer. ${ }^{10,11}$ This conflict cannot be easily resolved, because a prospective study to evaluate this variable and its possible confounding factors would be unethical. ${ }^{12}$
Therefore, we conducted a retrospective cohort study to determine if an increased delay between surgery and the first adjuvant treatment is a risk factor for lower overall survival among women with invasive breast cancer.

\section{Methods}

This was a retrospective cohort review. After ethics committee approval, we obtained from the digital program used to attend patients in the ambulatories a list with all cases registered in medical records coded as C50, according to the "International Code of Diseases". These women presented consecutively at the Oncology Service of a public academic hospital (Hospital Estadual Mário Covas - Santo André - Brazil) between January 2005 and December 2010. Data were, then, extracted from the medical records of all female patients with epithelial line invasive breast cancer already submitted to curative surgery. Since the authors were granted a waiver of consent by the ethics committee, these women were not contacted at all. 
Women with metastatic breast cancer at diagnosis, those who received neoadjuvant treatment, and those who did not undergo curative surgery or adjuvant treatment for any reason were excluded from the analysis. Patients who were missing any important medical record data (regarding their surgery or first adjuvant treatment) were also excluded.

For each case, the time between the date of definitive surgery and the date of the first adjuvant treatment was calculated. A cutoff for delay until treatment of 4 months or 120 days was established according to the guideline proposed by the American Society of Clinical Oncology (ASCO).${ }^{13}$ The overall survival was calculated as the time from diagnosis until death. Cases with follow-up loss were censored on the last date of contact.

Clinical and pathological data were also collected from original medical records, including age at diagnosis, histologic type (ductal vs. non-ductal), pathological stage according to the American Joint Committee on Can$\operatorname{cer}^{14}$ (I / II vs. III), number of positive axillary lymph nodes, tumor size, angiolymphatic invasion, perineural invasion, histologic grade (I / II vs. III), estrogen receptor status, HER2 status and type of adjuvant treatment (chemotherapy $v$ s. radiotherapy $v s$. hormone therapy).

For statistical analysis, the categorical data were expressed as absolute numbers and relative rates, and the continuous data were expressed as the means and standard deviation $(\mathrm{SD})$ or median and range. A Cox regression model was used for the univariate and multivariate analyses (backward likelihood ratio method) to calculate the hazard ratio (HR) with a $95 \%$ confidence interval (95CI). For the multivariate analysis, only the variables with $\mathrm{p}<0.20$ on univariate analysis were included. The Kaplan-Meier method was used to estimate the overall survival, and the log rank test was used to compare the survival curves. All analyses were performed using SPSS ${ }^{\circledast} 17.0$ (SPSS ${ }^{\circledast}$ Inc.; Illinois, USA). A p-value of less than $5 \%$ was considered significant.

\section{Results}

We included 348 consecutive women, with a median age of 57 years and a median time between surgery and first adjuvant treatment of 2 months (range: $0-11$ months). The majority had invasive ductal carcinoma $(75 \%)$ and was classified as having early stage breast cancer (77\%). The mean tumor size was $2.6 \mathrm{~cm}$, and the mean number of positive axillary lymph nodes was 2.6. Estrogen receptor was positive in $78 \%$ of the patients, and only $10 \%$ of the patients were Her2-positive. The first adjuvant treatment was chemotherapy in $59 \%$, radiotherapy in $28 \%$ and hormone therapy in $13 \%$ of the women. Nearly $10 \%$ of the women experienced delay in treatment longer than 4 months. A total of 23 deaths (6.6\%) occurred, including 18 out of 312 patients $(5.8 \%)$ in the group with delay between surgery and the first adjuvant treatment shorter than or equal to 4 months, and 5 out of 36 patients (13.9\%) in the group with delay longer than 4 months. Other relevant characteristics and the corresponding percentages of cases are listed in Table 1.

TABLE 1 Distribution of included patients according to the studied characteristics.

\begin{tabular}{|c|c|c|}
\hline \multirow[t]{2}{*}{ Characteristic } & \multicolumn{2}{|l|}{ Cases } \\
\hline & $\mathbf{n}$ & $\%$ \\
\hline Age* & 57 years $(27-92)$ & \\
\hline $\begin{array}{l}\text { Time from surgery until } 1^{\text {st }} \\
\text { adjuvant treatment* }\end{array}$ & 2 months $(0-11)$ & \\
\hline \multicolumn{3}{|l|}{ Delay to treatment } \\
\hline$\leq 4$ months & 312 & $89.6 \%$ \\
\hline$>4$ months & 36 & $10.4 \%$ \\
\hline \multicolumn{3}{|l|}{ Adjuvant treatment $\left(1^{\text {st }}\right)$} \\
\hline Chemotherapy & 205 & $58.9 \%$ \\
\hline Radiotherapy & 98 & $28.2 \%$ \\
\hline Hormone therapy & 45 & $12.9 \%$ \\
\hline \multicolumn{3}{|l|}{ Histologic type } \\
\hline Ductal carcinoma & 262 & $75.3 \%$ \\
\hline Non-ductal carcinoma & 86 & $27.7 \%$ \\
\hline \multicolumn{3}{|l|}{ Pathological stage } \\
\hline $1 / 11$ & 268 & $77.0 \%$ \\
\hline III & 80 & $23.0 \%$ \\
\hline Tumor size** & $2.6 \mathrm{~cm} \pm 1.7$ & \\
\hline Positive lymph nodes** & $2.6 \pm 4.2$ & \\
\hline \multicolumn{3}{|l|}{ Angiolymphatic invasion } \\
\hline No & 168 & $70.0 \%$ \\
\hline Yes & 72 & $30.0 \%$ \\
\hline \multicolumn{3}{|l|}{ Perineural invasion } \\
\hline No & 181 & $75.4 \%$ \\
\hline Yes & 59 & $24.6 \%$ \\
\hline \multicolumn{3}{|l|}{ Histologic grade } \\
\hline Grade I/II & 258 & $74.1 \%$ \\
\hline Grade III & 90 & $25.9 \%$ \\
\hline \multicolumn{3}{|l|}{ Estrogen receptor } \\
\hline Positive & 269 & $78.2 \%$ \\
\hline Negative & 75 & $21.8 \%$ \\
\hline \multicolumn{3}{|l|}{ HER2 status } \\
\hline Negative & 290 & $89.5 \%$ \\
\hline Positive & 34 & $10.5 \%$ \\
\hline
\end{tabular}

$\mathrm{N}=$ number of patients; * Median (range); ${ }^{*}$ Mean \pm standard deviation. 
The characteristics associated with worse overall survival in the univariate analysis were younger age, pathological stage, tumor size, number of positive axillary lymph nodes, angiolymphatic invasion, perineural invasion, histologic grade, estrogen receptor status, type of adjuvant treatment and time between surgery and the first adjuvant treatment (Table 2).

The multivariate analysis then indicated that time between surgery and the first adjuvant treatment (continuous variable) is an independent risk factor $(\mathrm{HR}=1.35,95 \mathrm{CI}$ $1.06-1.71, p=0.015$, Cox regression) for worse overall survival, along with negative estrogen receptor, the presence of angiolymphatic invasion and larger tumor size (Table 2). When the delay to adjuvant treatment was categorized using the 4-month cutoff and multivariate analysis was once again performed, the results were similar $(\mathrm{HR}=5.34$, 95CI $1.22-23.26, \mathrm{p}=0.026$, Cox regression).

The overall survival curves using ASCO's suggested cutoff also demonstrated that women with a delay between surgery and the first adjuvant treatment longer than 4 months had worse overall survival (72.6 vs. 80.9\%; $\mathrm{p}=0.041, \log$ rank test, Figure 1).

\section{Discussion}

In the present study, delay longer than 4 months between surgery and the first adjuvant treatment was found to be related to worse overall survival in patients with invasive breast cancer. Moreover, when considering time interval

\section{TABLE 2 Univariate and multivariate analysis with delay as a continuous variable.}

\begin{tabular}{|c|c|c|c|c|c|c|}
\hline \multirow[t]{2}{*}{ Characteristic } & \multicolumn{3}{|c|}{ Univariate analysis } & \multicolumn{3}{|c|}{ Multivariate analysis } \\
\hline & HR & $95 \mathrm{Cl}$ & $\mathbf{P}^{*}$ & HR & $95 \mathrm{Cl}$ & $\mathbf{p}^{*}$ \\
\hline Time from surgery until first adjuvant treatment & 1.13 & $0.96-1.33$ & 0.146 & 1.35 & $1.06-1.71$ & 0.015 \\
\hline \multicolumn{7}{|l|}{$1^{\text {st }}$ adjuvant treatment } \\
\hline Chemotherapy & 1.00 & & & 1.00 & & \\
\hline Radiotherapy & 0.35 & $0.12-1.04$ & 0.059 & 0.39 & $0.04-4.10$ & 0.369 \\
\hline Hormone therapy & 0.19 & $0.03-1.44$ & 0.108 & 1.43 & $0.13-15.6$ & 0.927 \\
\hline Age & 0.96 & $0.93-0.99$ & 0.039 & 1.01 & $0.96-1.06$ & 0.637 \\
\hline \multicolumn{7}{|l|}{ Histologic type } \\
\hline Ductal carcinoma & 1.00 & & & & $\mathrm{~N} / \mathrm{A}$ & \\
\hline Non-ductal carcinoma & 1.22 & $0.50-3.00$ & 0.669 & & & \\
\hline \multicolumn{7}{|l|}{ Pathological stage } \\
\hline $1 / 11$ & 1.00 & & & 1.00 & & \\
\hline III & 5.69 & $1.83-17.7$ & 0.030 & 1.76 & $0.27-11.3$ & 0.552 \\
\hline Tumor size & 1.34 & $1.13-1.59$ & 0.001 & 1.36 & $1.06-1.75$ & 0.016 \\
\hline Positive lymph nodes & 1.09 & $1.01-1.18$ & 0.022 & 0.91 & $0.78-1.05$ & 0.208 \\
\hline \multicolumn{7}{|l|}{ Angiovascular invasion } \\
\hline No & 1.00 & & & 1.00 & & \\
\hline Yes & 5.37 & $1.96-14.7$ & 0.001 & 4.85 & $1.21-19.4$ & 0.025 \\
\hline \multicolumn{7}{|l|}{ Perineural invasion } \\
\hline No & 1.00 & & & 1.00 & & \\
\hline Yes & 1.96 & $0.74-5.17$ & 0.172 & 0.83 & $1.17-4.13$ & 0.818 \\
\hline \multicolumn{7}{|l|}{ Histologic grade } \\
\hline Grade I/II & 1.00 & & & 1.00 & & \\
\hline Grade III & 5.27 & $0.67-41.3$ & 0.114 & 0.71 & $0.17-2.94$ & 0.635 \\
\hline \multicolumn{7}{|l|}{ Estrogen receptor } \\
\hline Positive & 1.00 & & & 1.00 & & \\
\hline Negative & 3.20 & $1.38-7.40$ & 0.007 & 3.58 & $1.01-12.7$ & 0.049 \\
\hline \multicolumn{7}{|l|}{ HER2 status } \\
\hline Negative & 1.00 & & & & $\mathrm{~N} / \mathrm{A}$ & \\
\hline Positive & 1.53 & $0.45-5.18$ & 0.493 & & & \\
\hline
\end{tabular}




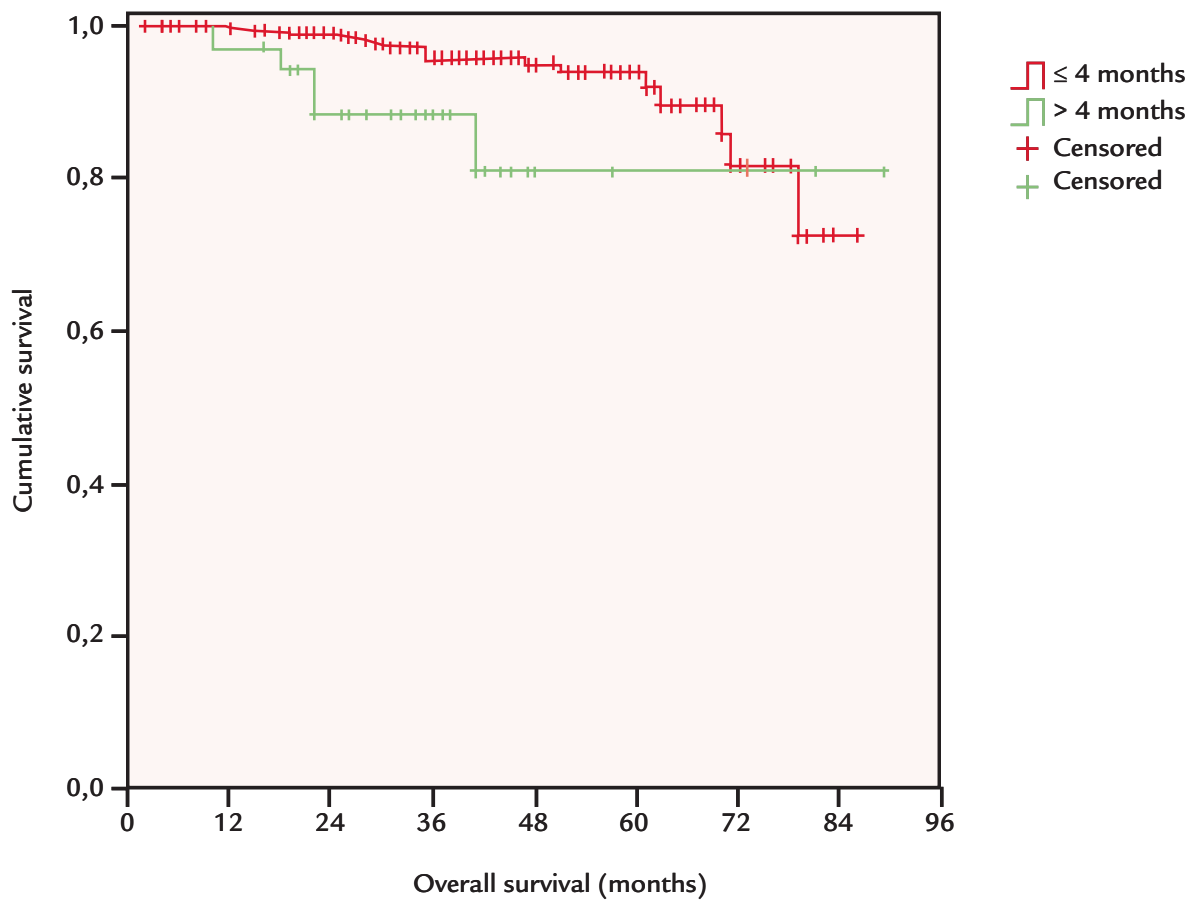

FIGURE 1 Kaplan-Meier curves showing that women with delay between surgery and the first adjuvant treatment longer than 4 months had a worse overall survival than those with this interval shorter than or equal to 4 months ( 72.6 vs. $80.9 \%$; $=0.041, \log$ rank test).

as a continuous variable, the risk of death was increased 1.3 -fold for each month of delay, independently of other well-established factors.

Since 2006, our group has been studying treatment delays in patients with breast cancer. In our first report, we analyzed the intervals between the first symptom and medical evaluation, biopsy and treatment, and found that the largest delay was that from the first abnormality noted by the patient and scheduling of the first medical appointment. ${ }^{15}$ Then, we conducted another study to identify potential delays in the management of patients with breast cancer, including medical suspicion, diagnosis and treatment. In this report, we found that the longest delay occurred between mammographic suspicion and biopsy, and that such delay was significantly longer in patients with advanced-stage breast cancer. We also found that the median time between surgery and the first adjuvant treatment was 1 month (varying between 0.5 to nearly 21 months). ${ }^{2}$ In this paper, our aim was to evaluate the delay between surgery and the first adjuvant treatment, based on a larger and more homogeneous group of consecutive patients with non-metastatic invasive breast cancer attended within a six-year period in a public hospital, and also to account for possible confounding factors.

The present study was conducted in a public hospital in a developing country where delays may be very long; we found a median interval of 2 months, a maximum delay of 11 months, and a rate of nearly $17 \%$ of patients who experienced an interval longer than 120 days ( 4 months). In an American study analyzing patients from the NCCN (National Comprehensive Cancer Network) database, Vandergrift et al. ${ }^{16}$ determined a median interval of approximately 6 weeks ( 1.5 months) between surgery and first adjuvant treatment; they also reported that $13 \%$ of the patients had a delay of more than 120 days.

The ideal interval between surgery and first adjuvant treatment is not yet well established in the literature. Richards et al. ${ }^{17}$ reported that delays longer than 12 weeks to first adjuvant treatment negatively affect survival of breast cancer patients. Lohrisch et al. ${ }^{18}$ also found lower overall survival in patients with intervals longer than 90 days. In contrast, there are several studies that indicate otherwise, i.e., that delays in adjuvant treatment do not influence survival. ${ }^{9,12,19,20}$ This controversy can be due to confounding factors, such as different patients selected and differ- 
ent cutoffs to establish an interval as a delay. In a recent report, Gagliato et al. ${ }^{21}$ showed that overall survival was influenced by adjuvant treatment delays longer than 60 days only in patients with known factors for worse prognosis, such as triple negative breast cancer or trastuzumab-treated Her2-positive breast cancer. A guideline from ASCO suggests that the duration between diagnosis and treatment should not exceed 120 days; they consider this a "reasonable estimate of the time need to deliver the preceding components of therapy that would not jeopardize outcome" ${ }^{13}$ Because this reasonable time estimate was given by a panel of specialists and was based on the current literature, this was the cutoff established to categorize the delay of treatment in the present study.

The limitations of this study were inherent to a retrospective design: missing data, loss of follow-up, different adjuvant treatments over time, as well as different treating physicians. Also, demographic data were lacking in medical records which can somehow bias our results, although this was a very homogeneous cohort once all patients were from underprivileged areas, with no medical insurance. Regarding its strengths, the most important aspect of this study was its use of delay as a continuous variable (it was the first study to do this, to our knowledge), which was adjusted for possible confounding factors; this method produced a more precise and clinically relevant result, i.e., that each month of delay progressively worsens overall survival.

\section{Conclusion}

This study showed that greater time intervals between surgery and the first adjuvant treatment lead to a worse prognosis among women with invasive breast cancer. These findings cannot be confirmed in a prospective trial, and observational studies are the most powerful evidence. Based on these results, we recommend further strategies to decrease the interval between surgery and the first adjuvant treatment.

\section{Resumo}

Atraso no tratamento adjuvante em pacientes com câncer de mama

Objetivo: avaliar se o tempo da cirurgia até o primeiro tratamento adjuvante (quimioterapia, radioterapia ou hormonioterapia) em pacientes com câncer de mama é um fator de risco para pior sobrevivência global (SG).

Métodos: estudo retrospectivo em que foram coletados dados dos prontuários de todas as mulheres com câncer de mama invasivo, diagnosticadas entre janeiro de 2005 e dezembro de 2010, atendidas consecutivamente em um serviço acadêmico de oncologia.

Resultados: foram incluídas 348 mulheres, com mediana de tempo entre a cirurgia e o primeiro tratamento adjuvante de 2 meses. A sobrevivência global foi pior entre as mulheres com maior tempo entre a cirurgia e o primeiro tratamento adjuvante. Após análise multivariada, essa variável permaneceu como fator de risco independente para SG, juntamente com receptor de estrógeno negativo, presença de invasão angiolinfática e maior tamanho tumoral. Conclusão: o tempo entre a cirurgia e o primeiro tratamento adjuvante é um fator de risco independente para a sobrevivência global de mulheres com câncer de mama invasivo.

Palavras-chave: neoplasias da mama, tempo para o tratamento, prognóstico, sobrevivência, garantia da qualidade dos cuidados de saúde.

\section{References}

1. INCA. Estimativa 2012: incidência de câncer no Brasil / INCA (Instituto Nacional do Câncer). Rio de Janeiro: INCA, 2011. 118p.

2. Trufelli DC, Miranda V da C, Santos MB, Fraile NM, Pecoroni PG, Gonzaga Sde F, et al. Analysis of delays in diagnosis and treatment of breast cancer patients at a public hospital. Rev Assoc Med Bras. 2008; 54(1):72-6.

3. Arriagada R, Le MG, Dunant A, Tubiana M, Contesso G. Twenty-five years of follow-up in patients with operable breast carcinoma: correlation between clinicopathologic factors and the risk of death in each 5 -year period. Cancer. 2006; 106(4):743-50.

4. Fan YP, Liu CL, Chiang IJ, Lin CY. Development of a prognostic nomogram for identifying those factors which influence the 2- and 5-year survival chances of Taiwanese women diagnosed with breast cancer. Eur J Cancer Care. $2011 ; 20(5): 620-6$

5. Schmidt M, Victor A, Bratzel D, Boehm D, Cotarelo C, Lebrecht A, et al. Longterm outcome prediction by clinicopathological risk classification algorithms in node-negative breast cancer--comparison between Adjuvant!, St Gallen, and a novel risk algorithm used in the prospective randomized Node-NegativeBreast Cancer-3 (NNBC-3) trial. Ann Oncol. 2009; 20(2):258-64.

6. Jung SY, Sereika SM, Linkov F, Brufsky A, Weissfeld JL, Rosenzweig M. The effect of delays in treatment for breast cancer metastasis on survival. Breast Cancer Res Treat. 2011; 130(3):953-64.

7. Gorin SS, Heck JE, Cheng B, Smith SJ. Delays in breast cancer diagnosis and treatment by racial/ethnic group. Arch Intern Medicine. 2006; 166(20):2244-52.

8. Lund MJ, Brawley OP, Ward KC, Young JL, Gabram SS, Eley JW. Parity and disparity in first course treatment of invasive breast cancer. Breast Cancer Res Treat. 2008; 109(3):545-57.

9. Smith ER, Adams SA, Das IP, Bottai M, Fulton J, Hebert JR. Breast cancer survival among economically disadvantaged women: the influences of delayed diagnosis and treatment on mortality. Cancer Epidemiol Biomarkers Prev. 2008; 17(10):2882-90.

10. Elmore JG, Nakano CY, Linden HM, Reisch LM, Ayanian JZ, Larson EB. Racial inequities in the timing of breast cancer detection, diagnosis, and initiation of treatment. Medical Care. 2005; 43(2):141-8.

11. Hershman D, McBride R, Jacobson JS, Lamerato L, Roberts K, Grann VR, et al. Racial disparities in treatment and survival among women with earlystage breast cancer. J Clin Oncol. 2005; 23(27):6639-46.

12. Brazda A, Estroff J, Euhus D, Leitch AM, Huth J, Andrews V, et al. Delays in time to treatment and survival impact in breast cancer. Ann Surg Oncol. 2010; 17(Suppl 3):291-6. 
13. Desch CE, McNiff KK, Schneider EC, Schrag D, McClure J, Lepisto E, et al. American Society of Clinical Oncology/National Comprehensive Cancer Network Quality Measures. J Clin Oncol. 2008; 26(21):3631-7.

14. AJCC. Cancer staging manual / AJCC (American Joint Committee on Cancer). 7.ed. New York: Springer-Verlag, 2010. 347p.

15. Trufelli DC, Bensi CG, Pane CEV, Ramos E, Otsuka FC, Tannous NG, et al. Onde está o atraso? Avaliação do tempo necessário para o diagnóstico e tratamento do câncer de mama nos serviços de oncologia da Faculdade de Medicina do ABC. Rev Bras Mastol. 2007; 17(1):14-8.

16. Vandergrift JL, Niland JC, Theriault RL, Edge SB, Wong YN, Loftus LS, et al. Time to adjuvant chemotherapy for breast cancer in National Comprehensive Cancer Network institutions. J Natl Cancer Inst. 2013; 105(2):104-12.

17. Richards MA, Smith P, Ramirez AJ, Fentiman IS, Rubens RD. The influence on survival of delay in the presentation and treatment of symptomatic breast cancer. Br J Cancer. 1999; 79(5-6):858-64
18. Lohrisch C, Paltiel C, Gelmon K, Speers C, Taylor S, Barnett J, et al. Impact on survival of time from definitive surgery to initiation of adjuvant chemotherapy for early-stage breast cancer. J Clin Oncol. 2006; 24(30): 4888-94.

19. Cold S, During M, Ewertz M, Knoop A, Moller S. Does timing of adjuvant chemotherapy influence the prognosis after early breast cancer? Results of the Danish Breast Cancer Cooperative Group (DBCG). Br J Cancer. 2005; 93(6):627-32.

20. Eastman A, Tammaro Y, Moldrem A, Andrews V, Huth J, Euhus D, et al. Outcomes of delays in time to treatment in triple negative breast cancer. Ann Surg Oncol. 2013; 20(6):1880-5.

21. Gagliato Dde M, Gonzalez-Angulo AM, Lei X, Theriault RL, Giordano SH, Valero V, et al. Clinical impact of delaying initiation of adjuvant chemotherapy in patients with breast cancer. J Clin Oncol. 2014; 32(8):735-44. 